\title{
소규모 위험물제조소의 안전관리 개선방안 Measures to Improve Safety Management of Small-Scale Hazardous Substance Factories
}

\author{
권혁식* . 곽대훈** . 고왕열*** \\ Kwon, Hyeogsic*, Kwak, Dae-Hoon**, and Ko, Wangyoul ${ }^{* * *}$
}

\begin{abstract}
Although fires in plants that manufacture hazardous materials do not occur frequently, the damages caused in a single such event are relatively large. Thus, it is essential to establish a safety management system for such factories. The primary aim of this study is to propose the improvement measures based on the analysis of standards according to the Dangerous Substances Safety Management Act, fire site surveys, and complete inspection of small-scale factories manufacturing dangerous substances. The specifications of the open holding area should be greater in number than the designated quantity; for example, the lightning rods should be mandatorily installed in a quantity of 10 times or more than the designated one. Other suggested measures include mandatory preparation of preventive regulations and regular inspection of all manufacturing plants by an external safety management agency, mandatory reporting and on-the-job training for substitutes of hazardous substance safety managers, and conducting a minimum qualification test for the post of safety manager and ensure that only those who have passed the test are employed. The existing laws and regulations should be amended to ensure that accidents can be prevented through systematic safety management.
\end{abstract}

Key words : Small-scale Hazardous Substance Manufacturing Plants, Safety Management Agency, Hazardous Substance Safety Managers

\section{요 지}

위험물제조소 화재는 발생빈도는 낮으나 피해의 규모가 크므로 위험물안전관리법에 따른 기준, 화재현장조사서 및 소규모 제조소 위험물안전관리 전수검사 분석을 통하여 다음과 같은 개선방안을 제시하였다. 지정수량 배수에 따른 보유공지 세분화, 지정수량 10 배 이상인 경우 피뢰침 의무설치, 모든 제조소의 예방규정 작성 및 정기점검 의무화, 외부의 안전관리대행기관에서 실시하는 정기점검, 위험물안전관리자의 대리자에 대한 신고 및 실무교육 의무화, 위험물안전관리자 자격은 시험 합격자로 제한하는 등 관련법령을 개정하여 체계적인 안전관리를 통해 사고를 예방할 수 있도록 하여야 한다.

핵심용어 : 소규모 위험물제조소, 안전관리대행기관, 위험물안전관리자

\section{1. 서 론}

산업의 발전에 따라 공장 및 연구소에서 다양한 화학물질 을 저장, 취급하고 있고, 이에 따라 화학물질에 따른 화재 등의 사고가 발생하고 있다. 화학물질 중에는 위험물안전관 리법에 따라 위험물로 분류되는 물질이 다수이며 위험물안
전관리법에서 ‘위험물'은 ‘인화성 또는 발화성 등의 성질을 가지는 것으로서 대통령령이 정하는 물품'으로 정의하고 있어 화재발생 우려가 높거나 화재시 피해가 클 것으로 예상되는 물품으로 위험물을 저장, 취급하기 위해서는 관련 법령에서 정하는 기준에 따라 저장, 취급시설을 갖추고 관할 소방서에 허가를 받아야 한다.

*정회원, 충남대학교 안전과학과 석사과정(E-mail: gur3222@korea.kr)

Member, Master Student, Department of Safety Science, Chungnam National University

***충남대학교 국가안보융합학부 부교수(Tel: +82-42-821-5298, Fax: +82-42-822-5236, E-mail: dkwak@cnu.ac.kr)

Associate Professor, School of Integrated National Security Chungnam National University

***교신저자, 정회원, 우송정보대학 소방안전관리과 조교수(Tel: +82-42-629-6394, Fax: +82-42-629-6396, E-mail: firepe@daum.net)

Corresponding Author, Member, Assistant Professor, Department of Fire Safety Management, Woosong College 
2014년 11월 22일 대전광역시 대덕구 소재 반도체업체 (주디엔에프에서 화학약품 폭발로 화재가 발생하여 1 명이 사망하고 7명이 부상을 입었고(GOODMORNINGCC, 2014) Fig. 1과 같이 2015년 8월 12일 중국 텐진항 물류창고에서 보관 중이던 질산암모늄 폭발사고로 173 명이 사망 또는 실종되고, 800 여명의 부상자가 발생하였으며 주변 아파트. 공장 등 건물 300여채가 파손되었다(NEWS1, 2016). 2018년 10 월 7일 경기도 고양시 대한송유관공사 경인지사에서 풍등 에 의해 발생한 화재에 의해 저장된 휘발유 등이 연소하면서 43 억 5 천만 원의 재산피해가 발생하였고 인근 주민들이 불안해하는 사고가 발생하였다(HANKOOKILBO, 2018). 2021년 3월 18일 오전 1시 52분에는 충남 논산시 노성면 두사리의 $\mathrm{LCD}$ 제조공장에서 폭발과 함께 불이나 1 명이 숨지고 9명이 중경상을 입는 사고가 발생하였다. 이날 불로 공장건물 7 개동 전체 $\left(3,032 \mathrm{~m}^{2}\right)$ 가 탔으며 인화성고체 등 5 종, 메틸알코올 등 8 종을 보관하고 있었던 것으로 나타났다 (NEWS1, 2021).

이 외에도 많은 위험물 관련 화재사고가 발생하고 있으나 일반인들 사이에서는 위험물시설에서 발생한 화재사고를 구분할 수 없으므로 위험물에 대한 위험성을 인지하기 어려 웠으나 경기도 고양시 대한송유관공사 화재사고를 통하여 위험물 화재의 위험성에 대해 일반인들이 인식하는 계기가 되었을 것으로 생각한다.

이처럼 일반인들의 인식에 비해 위험물로 인한 화재는 많이 발생하고 있으며 위험물로 인한 화재는 피해의 규모가 일반화재에 비해 클 수밖에 없다. 앞서 언급한 바와 같이 위험물안전관리법에서는 위험물의 저장, 취급량에 따라 시 설의 설치기준이 달라지게 되고 소방기관에서도 위험물제 조소등으로 허가를 받은 특정소방대상물에 대하여는 화재 예방에 특별히 주의하여 관리를 하고 있으나 위험물의 저장, 취급수량이 많은 대형 제조소등에 더 많은 비중을 두고 있으므로 본 연구에서는 위험물안전관리법에서 정한 기준 을 검토하고, 논산소방서에서 작성한 '타코마테크놀러지(주)

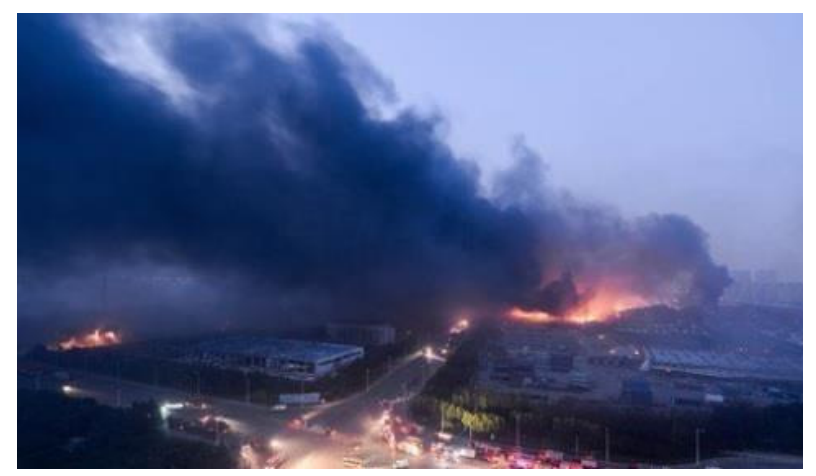

(a) Explosion of warehouse in Tianjin Port (NEWS1, 2016)
화재현장조사서, 및 2021년 5월부터 6월까지 소방청에서 실시한 '소규모 제조소 위험물 안전관리 전수검사 결과'를 분석하여 소규모 위험물제조소의 안전관리 개선방안을 제 시하도록 하겠다.

\section{2. 위험물 시설기준 등}

\section{1 제조소등의 정의}

위험물안전관리법에서 ‘위험물'은 ‘인화성 또는 발화성 등의 성질을 가지는 것으로서 대통령령이 정하는 물품'으로 정의하고 있으며 '제조소등'은 '제조소, 저장소 및 취급소'를 말한다. ‘제조소'는 ‘위험물을 제조할 목적으로 지정수량 이상의 위험물을 취급하기 위하여 동법 규정에 따른 허가를 받은 장소'로 ‘저장소'는 ‘지정수량 이상의 위험물을 저장하 기 위하여 대통령령이 정하는 장소로 동법 규정에 따른 허가를 받은 장소', ‘취급소'는 ‘지정수량 이상의 위험물을 제조외의 목적으로 취급하기 위하여 대통령령이 정하는 장소로 동법 규정에 따른 허가를 받은 장소'로 정의되어 있다. 큰 분류로 ‘제조소', ‘저장소', ‘취급소'로 구분되어 있으며 통칭하여 ‘제조소등'으로 정의하고 있다. ‘지정수량' 은 ‘위험물의 종류별로 위험성을 고려하여 대통령령이 정하 는 수량으로 제조소등의 설치허가 등에 있어서 최저의 기준 이 되는 수량'을 말하며 지정수량 이상의 위험물을 제조, 저장, 취급하는 경우 허가를 받도록 규정하고 있다. 지정수량 은 위험물안전관리법 시행령 제 2 조 및 제 3 조 관련 별표에서 크게 1 류 6 류로 구분하고 있으며 각 류별 특성은 Table 1 과 같다.

위험물안전관리법에서는 제조소를 규모에 따라 소규모 등으로 분류하지 않으며 지정수량 이상의 위험물을 저장, 취급하는 경우에만 동법 기준을 따르도록 하고 있고 지정수 량 미만인 위험물의 저장 및 취급에 관하여는 시 · 도 조례에 따라 별도로 기술상의 기준을 정하고 있으나 위험물안전관 리법에 따른 허가 대상시설이 아니다. '제조소의 위치·구조

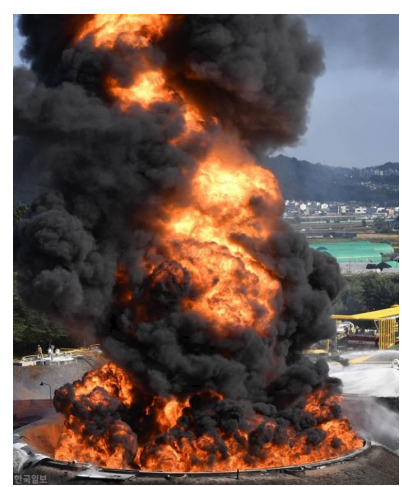

(b) Oil tank fire in Goyang-si (HANKOOKILBO, 2018)

Fig. 1. Hazardous Substance Fire Case 
및 설비의 기준'은 위험물안전관리법 시행규칙 별표4에서 정하고 있으며 해당 기준에서도 소규모 위험물제조소를 별도로 규정하고 있지 않지만 보유공지(위험물을 취급하는 건축물 그 밖의 시설의 주위에 그 취급하는 위험물의 최대수 량에 따라 보유하여야 하는 공지)를 확보하도록 하는 규정에 는 지정수량의 10 배 이하와 10 배 초과로 구분하여 10 배 이하인 경우 공지의 너비를 $3 \mathrm{~m}$ 이상, 10 배 초과인 경우 $5 \mathrm{~m}$ 이상 확보하도록 구분하고 있다. 소방청에서 실시한 '소규모 제조소 위험물 안전관리 전수검사 결과'에서도 소규 모 제조소에 대하여 별도로 규정하지 않았으나 검사대상을 '지정수량 10 배 미만 제조소 780 개소'로 지정하여 지정수량 의 10 배 미만인 제조소를 소규모 제조소로 분류하고 있는 것으로 볼 수 있다. 다만, ‘제조소의 위치 - 구조 및 설비의 기준'에서는 지정수량의 10 배 이하, 소방청에서는 지정수량 의 10 배 미만으로 구분하여 혼란이 발생할 수 있으므로

Table 1. Characteristics of Classification

\begin{tabular}{c|c}
\hline & Characteristics of classification \\
\hline Class 1 & Oxidizer of liquid \\
\hline Class 2 & Combustible of solid \\
\hline Class 3 & Pyrophfic meterials and water reactive \\
& materials \\
\hline Class 4 & Flammable liquid \\
\hline Class 5 & Oxidizer of Solid \\
\hline Class 6 &
\end{tabular}

소규모 제조소라는 용어를 사용하고자 하는 경우 소규모 제조소에 대한 정의를 지정수량의 10 배 미만으로 통일하여 정의하는 것이 좋을 것으로 판단된다.

\section{2 제조소의 설치기준 및 운영}

위험물안전관리법 시행규칙 별표4 '제조소의 위치· 구조 및 설비의 기준'에 따라 제조소에 설치하거나 적용하여야 하는 주요 항목은 ‘안전거리', ‘보유공지', ‘표지 및 게시판' '건축물의 구조', ‘채광·조명 및 환기설비', ‘배출설비', ‘옥 외설비의 바닥', ‘기타설비’로 구성되어 있으며 아래에서는 이 항목들의 설치기준, 제조소의 규모 등에 따라 달리 적용되 는 규정, 그 외에 위험물안전관리법 내용 중 제조소의 운영과 관련한 항목에 대하여 검토하도록 하겠다.

\subsection{1 안전거리}

제조소는 다중이 이용하거나 보존하여야 할 문화재, 위험 이 증가될 수 있는 시설 등 동 기준에 따른 다른 건축물의 외벽 또는 이에 상당하는 공작물의 외측으로부터 당해 제조 소의 외벽 또는 이에 상당하는 공작물의 외측까지의 사이에 수평거리를 지정수량의 배수와 관계없이 동일하게 두도록 하여 제조소에서의 화재나 폭발등에 대비하도록 하고 있으 나 미국의 경우 위험물질의 분류체계 및 저장, 취급시설에 대한 기준이 다르게 규정되어 있어 저장 또는 취급하는 위험물의 양이나 보호수준에 따라 안전거리를 다르게 적용 하고 있어 우리나라도 위험물의 양에 따라 안전거리를 다르 게 적용해야할 필요가 있다. Table 2는 NFPA 400 에 기재된

Table 2. American Table of Distances

\begin{tabular}{|c|c|c|c|c|c|c|c|c|c|}
\hline \multirow{2}{*}{\multicolumn{2}{|c|}{$\begin{array}{c}\text { Quantity of Explosive } \\
\text { Materials }\end{array}$}} & \multicolumn{8}{|c|}{ Distances in Feet } \\
\hline & & \multicolumn{2}{|c|}{ Inhabited Buildings } & \multicolumn{2}{|c|}{$\begin{array}{c}\text { Public Highways Traffic } \\
\text { Volume of } 3,000 \\
\text { Vehicles/Day or Less }\end{array}$} & \multicolumn{2}{|c|}{$\begin{array}{l}\text { Passenger Railways- } \\
\text { Public Highways with } \\
\text { Traffic Volume of More } \\
\text { Than 3,000 Vehicles/Day }\end{array}$} & \multicolumn{2}{|c|}{$\begin{array}{l}\text { Separation of } \\
\text { Magazines }\end{array}$} \\
\hline $\begin{array}{c}\text { Pounds } \\
\text { Over }\end{array}$ & $\begin{array}{c}\text { Pounds Not } \\
\text { Over }\end{array}$ & Barricated & $\begin{array}{c}\text { Un- } \\
\text { Barricated }\end{array}$ & Barricated & $\begin{array}{c}\text { Un- } \\
\text { Barricated }\end{array}$ & Barricated & $\begin{array}{c}\text { Un- } \\
\text { Barricated }\end{array}$ & Barricated & $\begin{array}{c}\text { Un- } \\
\text { Barricated }\end{array}$ \\
\hline 0 & 5 & 70 & 140 & 30 & 60 & 51 & 102 & 6 & 12 \\
\hline 5 & 10 & 90 & 180 & 35 & 70 & 64 & 128 & 8 & 16 \\
\hline 10 & 20 & 110 & 220 & 45 & 90 & 81 & 162 & 10 & 20 \\
\hline 20 & 30 & 125 & 250 & 50 & 100 & 90 & 186 & 11 & 22 \\
\hline 30 & 40 & 140 & 280 & 55 & 110 & 103 & 206 & 12 & 24 \\
\hline 40 & 50 & 150 & 300 & 60 & 120 & 110 & 220 & 14 & 28 \\
\hline 50 & 75 & 170 & 340 & 70 & 140 & 127 & 254 & 15 & 30 \\
\hline 75 & 100 & 190 & 380 & 75 & 150 & 139 & 278 & 16 & 32 \\
\hline 100 & 125 & 200 & 400 & 80 & 160 & 150 & 300 & 18 & 36 \\
\hline \multicolumn{10}{|c|}{ 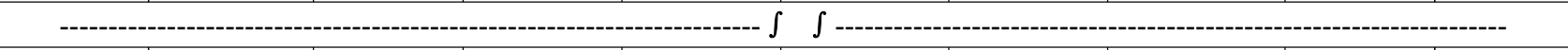 } \\
\hline 230,000 & 250,000 & 2,155 & 2,155 & 650 & 1,300 & 1,890 & 2,000 & 335 & 670 \\
\hline 250,000 & 275,000 & 2,215 & 2,215 & 670 & 1,340 & 1,950 & 2,000 & 360 & 720 \\
\hline 275,000 & 300,000 & 2,275 & 2,275 & 690 & 1,380 & 2,000 & 2,000 & 385 & 770 \\
\hline
\end{tabular}


보호수준1에 해당하는 저장소 및 취급소의 안전거리기준표 이며 표에서는 일부 구간이 생략되어 있으나 70 개의 구간으로 세분화 되어 있다(National Fire Protection Association, 2019).

\subsection{2 보유공지}

위험물을 취급하는 건축물 그 밖의 시설의 주위에 그 취급하는 위험물의 최대수량에 따라 Fig. 2 와 같이 공지를 확보해야하며 취급하는 위험물의 최대수량이 지정수량의 10 배 이하인 경우 $3 \mathrm{~m}$ 이상, 10 배 초과인 경우 $5 \mathrm{~m}$ 이상으로 단순하게 분류되어 있다. 보유공지는 소화활동 등을 위하여 필요한 공간이므로 넓을수록 좋겠으나 지정수량의 10 배 초과인 경우 $5 \mathrm{~m}$ 이상으로 규정되어 있어 세분화할 필요가 있으며 옥내저장소 등의 위험물 저장시설과 비교하여도 지정수량의 배수 및 건축물의 구조에 따라 세분화되어 있는 것에 비하면 너무 단순하게 분류되어 있다. Table 3 은 여러 가지 위험물 저장소 중에 옥내저장소의 보유공지 기준으로 제조소에 비해 비교적 상세하게 분류되어 있으며 '지정수량의 200 배 초과'에 해당하는 경우 내화구조의 건축물은 $10 \mathrm{~m}$ 이상, 그 밖의 건축물은 $15 \mathrm{~m}$ 이상이고, 옥외탱크저장소 및

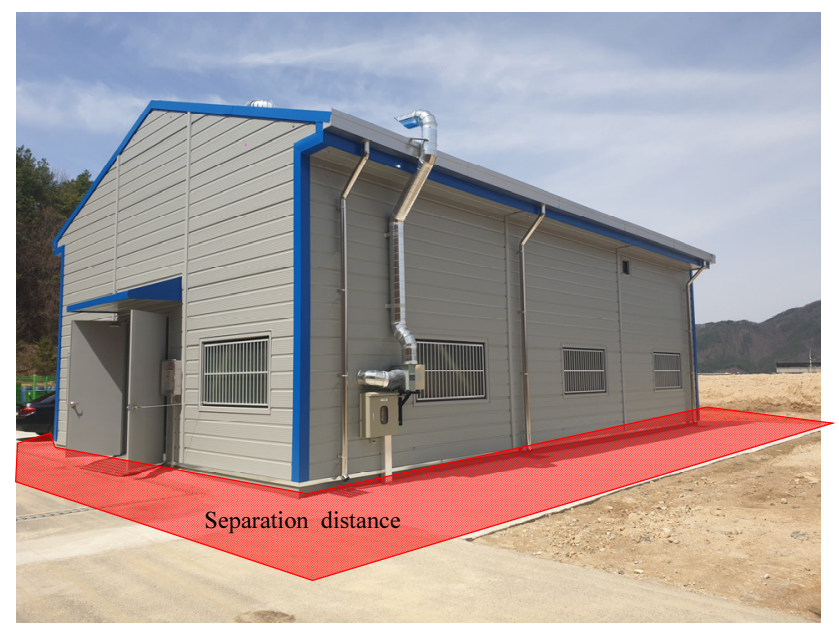

Fig. 2. Separation Distance
옥외저장소의 경우에도 최대 보유공지가 $15 \mathrm{~m}$ 이상인 것에 비하면 제조소의 보유공지 구분이 단순하게 되어있다는 것을 확인할 수 있다. 일반적으로 제조소용도의 건축물이 저장소 용도의 건축물보다 큰 경우가 많아 단위면적당 저장 또는 취급하는 위험물의 양이 적어질 수도 있으나 소화활동 측면에서는 건축물의 규모가 커지면 소화활동이 어려워지 고 소화활동에 필요한 공간이 오히려 커져야할 필요가 있으 므로 제조소의 보유공지도 취급하는 위험물의 양에 따라 세분화 할 필요가 있다.

\subsection{3 피뢰설비}

지정수량의 10 배 이상의 위험물을 취급하는 제조소에는 피뢰침을 설치하도록 하고 있으며 제조소 주위의 상황에 따라 안전상 지장이 없는 경우에는 피뢰침을 설치하지 아니 할 수 있도록 규정하고 있다. 제조소등은 지정수량 이상의 위험물을 제조, 저장, 취급하기 위한 시설로 위험물안전관리 법상 위험성을 가지고 있는 시설로 구분되어 있는 만큼 주위상황에 따라 안전상 지장이 없는 경우를 제외하고 지정 수량의 배수와 무관하게 피뢰침을 설치하도록 하여야 한다.

\subsection{4 예방규정}

지정수량의 10 배 이상의 위험물을 취급하는 제조소의 경우 예방규정을 정하여 당해 제조소 등의 사용을 시작하기 전에 시·도지사에게 제출하여야 하며 예방규정은 당해 제조소등의 화재예방과 화재 등 재해발생시의 비상조치를 위한 여러 가지 사항이 포함되어 있다. 화재예방, 소방시설설 치 - 유지 및 안전관리에 관한 법률(이하 ‘소방시설법’)에서 는 특정소방대상물을 특급, 1 급, 2 급, 3 급 소방안전관리대상 물로 구분하여 소방안전관리자를 선임하고 소방안전관리자 는 소방계획서를 작성하도록 하고 있으며, 이는 위험물안전 관리법에서 위험물안전관리자를 선임하도록 하고 예방규정 을 작성하는 것과 유사한 것으로 볼 수 있다. 소방시설법에서 특정소방대상물의 소방계획서 작성의무를 규모에 따라 구 분을 두지 아니하는 것과 같이 제조소에서도 규모와 무관하 게 예방규정을 작성하도록 의무화하여야 한다.

Table 3. Separation Distance of Indoor Storage

\begin{tabular}{l|c|c}
\hline \multicolumn{1}{c|}{ Maximum quantity of hazardous substance to be stored } & $\begin{array}{c}\text { Separation distance } \\
\text { columns and floors are } \\
\text { fire-resistan }\end{array}$ & - \\
\cline { 2 - 4 } & Other buildings & More than $0.5 \mathrm{~m}$ \\
\hline Less than 5 times the designated quantity & More than $1 \mathrm{~m}$ & More than $1.5 \mathrm{~m}$ \\
\hline More than 5 times and less than 10 times the designated quantity & More than $2 \mathrm{~m}$ & More than $3 \mathrm{~m}$ \\
\hline More than 20 times and less than 50 times the designated quantity & More than $3 \mathrm{~m}$ & More than $5 \mathrm{~m}$ \\
\hline More than 50 times and less than 200 times the designated quantity & More than $5 \mathrm{~m}$ & More than $15 \mathrm{~m}$ \\
\hline More than 200 times the designated quantity & More than $10 \mathrm{~m}$ & $10 \mathrm{~m}$ \\
\hline
\end{tabular}




\subsection{5 정기점검}

지정수량의 10 배 이상의 위험물을 취급하는 제조소는 '제조소등의 위치·구조 및 설비의 기술기준'에 적합한지의 여부를 정기적으로 점검(이하 ‘정기점검')하고 점검결과를 기록하여 보존하도록 하고 있으나 제조소는 위험물을 제조 할 목적으로 지정수량의 위험물을 취급하기 위하여 허가를 받은 대상이므로 정기점검 대상을 지정수량의 10 배 이상으 로 제한할 필요 없이 모든 제조소에 정기점검을 실시하도록 의무화하여야 한다.

Park et al. (2020)은 '위험물 안전관리 제도의 개선에 관한 연구'에서 '예방규정 작성대상 제조소를 포함한 지하탱 크저장소, 이동탱크저장소, 위험물을 취급하는 탱크로서 지하에 매설된 탱크가 있는 제조소·주유취급소 또는 일반 취급소에 연 1 회 이상 제조소등의 관계인으로 하여금 정기점 검을 하도록 규정되어 있다. 이는 지정수량이상 정기점검 대상 미만의 많은 수의 제조소등에 대하여 소방검사의 사각 지대로 방치하는 결과를 초래하였다.'고 하여 소규모제조소 가 정기점검대상에서 제외된 문제에 대하여 언급하였다 (Park et al., 2020).

Lee (2021)은 '위험물안전관리대행 제도 개선 방안에 대 한 연구'에서 ‘위험물 제조소 등의 종합정밀점검과 작동기능 점검을 통하여 시설보완 및 위험물 사용 배관의 부식유무, 안전장치의 정상작동유무, 소방시설의 작동기능검사를 실 시하여 위험물 시설에 대한 안전사고를 사전에 예방할 수 있을 것이다라고 하여 위험물 제조소 등에 대하여 종합정밀 점검 및 작동기능점검을 실시하여야 한다고 하였다(Lee, 2021). 소방시설법에 따른 종합정밀점검과 작동기능점검과
같이 위험물시설을 점검하도록 하는 것도 유효하겠으나 소규모 제조소의 경우 기존의 법령에 의한 정기점검 제도를 보완하는 것으로도 일정수준의 안전이 확보될 것으로 판단 된다.

현행 위험물안전관리법에서는 자체적으로 정기점검을 실시한 후 점검결과를 기록하여 보존하도록 하고 있으나 2021년 10월 20일 이후로 정기점검을 실시하는 경우 그 결과를 시 - 도지사에게 제출하도록 의무화 하여 정기점검 의 실시여부를 관리할 수 있도록 신설하였다. 다만, 정기점검 의 주체를 안전관리자에 의해 실시하도록 하여 정기점검이 형식적인 형태를 띨 우려가 있으므로 법령을 정비하여 전문 적으로 점검을 실시하는 외부기관에 의해 실시하도록 하여 정기점검의 공정성을 확보할 수 있도록 하여야 할 것이다.

소방시설법에서는 소방시설관리업을 등록한 자가 소방 안전관리 업무의 대행 또는 소방시설등의 점검 및 유지· 관 리할 수 있도록 되어 있다. 위험물안전관리법에서도 Table 4 와 같이 인력과 시설, 장비를 갖춘 위험물 안전관리대행기 관에 의해 위험물안전관리자의 업무를 위탁받아 수행할 수 있도록 하는 규정이 있는 만큼 외부의 안전관리대행기관 에서 정기점검을 실시할 수 있도록 하고 정기점검에 관한 세부기준 등을 신설해야 한다. 또한 안전관리대행기관으로 등록할 수 있는 대상 기관에 ‘탱크시험자로 등록한 법인'이 나 '다른 법령에 의하여 안전관리업무를 대행하는 기관으로 지정, 승인 등을 받은 법인’만 등록할 수 있도록 제한하고 있어 위에서 언급한 두 가지 법인 이외에는 안전관리대행기 관으로 등록할 수 없으므로 안전관리대행기관으로 등록하 기 위한 신설법인이나 타 법인도 인력과 장비 등의 기준을

Table 4. Designation Criteria for Safety Management Agency

\begin{tabular}{|c|c|}
\hline & Detail \\
\hline $\begin{array}{l}\text { Organizations } \\
\text { that can be } \\
\text { designated }\end{array}$ & $\begin{array}{l}\text { 1. Organizations that can be designated } \\
\text { 2. A corporation that has been designated or approved as an agency acting on behalf of safety } \\
\text { management under other laws }\end{array}$ \\
\hline $\begin{array}{l}\text { Technical } \\
\text { Manpower }\end{array}$ & $\begin{array}{l}\text { 1. At least one Master Craftman Hazardous material or Industrial Engineer Hazardous material } \\
\text { 2. At least two Industrial Engineer Hazardous material or Craftman Hazardous material } \\
\text { 3. At least one Engineer Fire Protection System -Mechanical or Engineer Fire Protection System -Electrical }\end{array}$ \\
\hline Facility & Have a dedicated office \\
\hline Equipment & $\begin{array}{l}\text { 1. Insulation resistance meter } \\
\text { 2. Earth resistance meter (Minimum division } 0.1 \Omega \text { or less) } \\
\text { 3. Gas concentration meter (Hydrocarbon-type Measurable) } \\
\text { 4. Electrostatic Potentiometer } \\
\text { 5. Torque Wrench } \\
\text { 6. Vibration tester } \\
\text { 7. Surface Therometer }\left(-10{ }^{\circ} \mathrm{C} \sim 300{ }^{\circ} \mathrm{Ce}\right) \\
\text { 8. Thickness Gauge }(1.5 \mathrm{~mm} \sim 9.9 \mathrm{~mm}) \\
\text { 9. Safety equipment (Hard hat, Safety boots, Flashlight, Safety rope. etc.) } \\
\text { 10. Fire Extinguishing Equipment Inspection Device (Fire hydrant valve pressure gauge, Ejection pressure } \\
\text { gauge, Foam collector, Head wrench, Foam container) }\end{array}$ \\
\hline
\end{tabular}


갖춘 경우 등록할 수 있도록 기준을 개정하여야 한다. 다만, 소규모 제조소등으로서 점검대상시설이 적은 경우 기준을 정하여 일정수준의 자격을 갖춘 위험물안전관리자가 자체 적으로 정기점검을 실시할 수 있도록 예외규정을 정할 필요 가 있다.

\subsection{6 위험물안전관리자}

\subsubsection{1 위험물안전관리자의 자격}

위험물안전관리법에 따르면 위험물안전관리자는 위험물 의 취급에 관한 자격이 있는 자로 하고 있으며 위험물기능장, 위험물산업기사, 위험물기능사의 자격을 취득한 사람은 모 든 위험물, 안전관리자교육이수자 및 소방공무원 경력자는 제 4 류 위험물만을 취급할 수 있도록 하고 있다.

안전관리자 교육이수자로서 안전관리자가 되려는 사람 은 24시간의 강습교육을 이수하면 위험물안전관리자로 선 임되어 위험물을 취급할 수 있게 되며 시험을 치르지만 시험결과와 무관하게 위험물을 취급할 수 있게 되는 것으로 강습교육을 통해 안전관리자로서의 자질을 갖췃는지 여부 에 대하여 객관적으로 판단할 수 있는 근거가 없으며 소방공 무원 경력자 또한 소방공무원으로 근무한 경력이 3년 이상인 자로 자격을 제한하였으나 위험물 관련업무를 수행하지 아니한 경우 안전관리자로서의 자질을 갖추었다고 볼 수 없다.

Hyun et al. (2007)는 '위험물안전관리자 강습교육의 개선 방안에 관한 연구’에서 ‘위험물이 정상이 아닌 상태를 나타 내고, 그것을 통제할 수 없는 상황에 이르는 사고를 미연에 방지하기 위한 대응예방대책과 위험물제조소등에 대한 보 다 전문적이고, 체계적인 위험물 안전관리를 위한 강습교육 이 절실히 필요한 상황이다라고 하여 강습교육에 대한 보완 의 필요성을 주장하였다(Hyun et al., 2007).

소방시설법에 따라 특정소방대상물에 선임하여야 하는 소방안전관리자도 위험물안전관리자와 같이 특정분야의 경력으로 선임할 수 있는 자격을 주었으나 법령의 개정을 통하여 경력을 갖춘자로서 소방안전관리에 관한 시험에 합격한 사람만 자격을 부여하도록 하였다. 위험물안전관리 자 또한 강습교육을 받거나 소방공무원 경력자인 경우라도 위험물안전관리에 관한 시험에 합격한 사람에게만 자격을 부여하고 위험물안전관리자로서 업무를 수행하도록 하여야 한다.

\subsubsection{2 위험물안전관리자의 직무대행}

위험물안전관리법에 따르면 안전관리자를 선임한 제조 소등의 관계인은 안전관리자가 여행 - 질병 그 밖의 사유로 인하여 일시적으로 직무를 수행할 수 없거나 안전관리자의 해임 또는 퇴직과 동시에 다른 안전관리자를 선임하지 못하 는 경우에는 국가기술자격법에 따른 위험물의 취급에 관한 자격취득자 또는 위험물안전에 관한 기본지식과 경험이
있는 자로서 행정안전부령이 정하는 자를 대리자로 지정하 여 그 직무를 대행하게 하여야 하며 대리자가 안전관리자의 직무를 대행하는 기간은 30 일을 초과할 수 없다. 여기서 ‘위험물안전에 관한 기본지식과 경험이 있는 자'란 행정안전 부령이 정하는 자는 안전교육을 받은 자, 제조소등의 위험물 안전관리업무에 있어서 안전관리자를 지휘·감독하는 직위 에 있는 자로 규정되어 있다.

위험물안전관리자는 선임된 날로부터 6개월 이내, 그 이 후 2 년마다 1 회 8 시간 이내에 실무교육을 의무적으로 받아야 하나 대리자에게는 실무교육의 의무가 없다. 또한, 객관적으 로 증명되지 않은 ‘위험물안전에 관한 기본지식과 경험이 있는 자'에게 위험물안전관리자의 업무를 대리할 수 있도록 하는 것은 무자격자에게 위험물안전관리업무를 수행할 수 있도록 하는 것과 같다.

소방시설법에 따라 특정소방대상물에 선임하는 소방안 전관리자의 경우에도 특정소방대상물의 규모에 따라 일정 자격을 갖춘 소방안전관리보조자를 선임하도록 하고 실무 교육을 정기적으로 이수하도록 하고 있으므로 위험물안전 관리자의 대리자도 의무적으로 선임신고 및 실무교육을 이수하도록 하여 안전관리를 체계적으로 하여야 할 필요가 있다.

\section{3. 화재현장조사서 분석}

\section{1 화재발생 개오}

일시 : 2021년 3월 18일, 01시 52분

장소 : 논산시 노성면

대상 : 타코마테크놀러지(주)

인명피해 : 총 8명(사망1, 중상2, 경상5)

재산피해 : 4,862,749천원(NFDS, 2021)

\section{2 발생원인}

작업공정은 반응기를 이용한 제품 정제공정으로 광개시 제를 Hot Filter에서 수거하여 재투입하는 과정을 반복하는 공정으로 수거한 광개시제 재투입과정 중 해당공정에 들어 가지 않는 촉매제(염화알루미늄)가 작업자의 오인으로 반응 기에 투입되면서 내용물(9:1 비율의 이소프로필에테르와 에틸아세테이트 $2,000 \mathrm{~kg}$ 추정)이 분출하였고 분출을 막던 작업자가 부상을 입어 구급신고 후 대기하던 중 공장내 확산된 유증기가 미상의 점화원에 의하여 발화 폭발한 화재 이다.

위험물안전관리자 부재 상태에서 공정이 시행되었으며 Figs. 3(a), 3(b)와 같이 계량목적으로 작업장으로 이동한 촉매가 검정 비닐에 담겨 방치되어 있었고 Hot Filter에서 수거된 광개시제도 검정비닐에 담겨져 보관되어 작업자가 오인하여 광개시제 대신 촉매를 투입하였고 이상반응에 따라 반응기 내부의 내용물이 분출하여 발생한 사고로 추정 


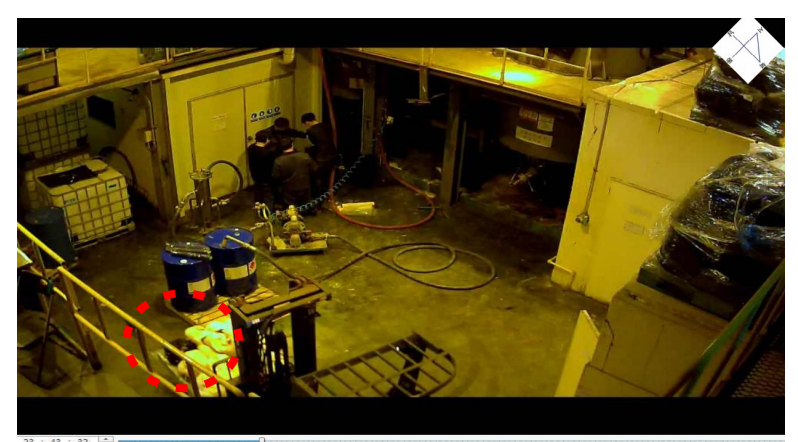

(a) Catalyst neglect (Black vinyl)

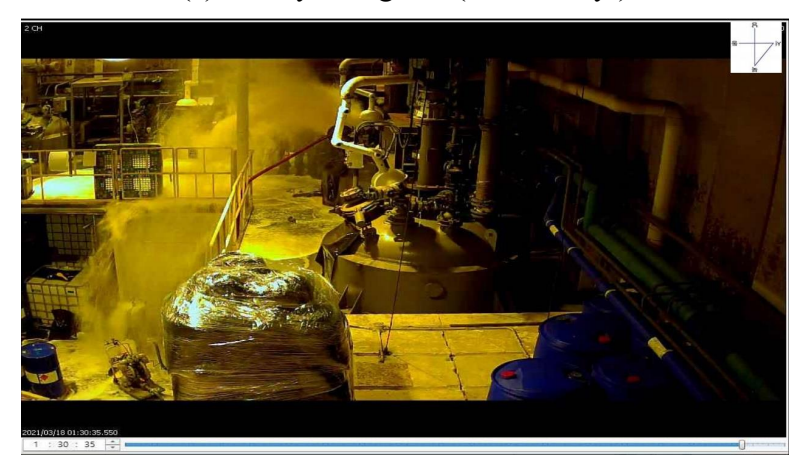

(b) Content ejection

Fig. 3. CCTV Capture

하고 있다(NFDS, 2021).

\section{3 화재감식 결과}

발화요인은 유증기 확산으로 인한 화학적 발화로 추정하 고 있으며 최초착화물 및 연소확대물은 제 4 류 위험물(이소 프로필에테르 등)로 추정하고 있으며 발화원은 미상으로 판단하고 있다(NFDS, 2021).

\section{4 문제점 분석}

다른 종류의 물질을 동일한 검정색 비닐봉투에 보관하여 반응기에 오인 투입한 것이 직접적인 원인이나 위험물안전 관리자가 부재중인 상황에서 위험물을 취급하여 전문적인 지식이 없는 상태로 작업이 진행된 것도 큰 문제로 볼 수 있다. 위험물안전관리법에 따르면 위험물을 취급하는 작업 을 하는 때에는 작업자에게 안전관리에 관한 필요한 지시를 하는 등 위험물의 취급에 관한 안전관리와 감독을 하도록 하고 있으나 해당 기준이 준수되지 않은 것이다. 또한, 작업자 들도 취급하는 위험물의 위험성을 알고 있어야 하므로 공정 투입전에 작업자에 대하여 위험물안전관리자가 안전교육을 실시하도록 하여야 한다.

위험물안전관리법 시행규칙 [별표19] ‘위험물의 운반에 관한 기준’을 보면 운반용기의 외부에 품명, 수량, 화학명, 주의사항 등 경고표시를 하여야 한다고 규정하고 있으나 글자크기, 색깔 등은 규정하고 있지 않아 눈에 잘 띄지 않고
구분하기 쉽지 않으며, ‘위험물 운송·운반시의 위험성 경고 표지에 관한 기준'에서는 이동탱크저장소 또는 위험물 운반 차량에 부착하는 위험성 경고표지에 관한 사항을 규정하고 있으나 공장 내부에서 계측하여 작업에 투입하는 과정에서 는 해당기준을 적용하기 어렵다. 따라서, 위험물안전관리자 는 위험물을 취급하는 제조소나 취급소에서 다른 종류의 물질을 옮겨 담거나 이동하는 경우 외형이 뚜렷이 구분되는 용기를 사용하거나 문자의 기재등으로 쉽게 식별할 수 있도 록 조치를 취하여야 한다.

또한, 위험물안전관리자가 근무하지 아니하는 시간에 위 험물을 취급하는 경우 대리자가 근무할 수 있도록 하여야 하고, 대리자는 위에서 언급한 바와 같이 위험물 취급에 관한 자격이 있는 자에게 자격을 주고 선임신고도 의무화 할 필요가 있다.

\section{4. 소규모 제조소 위험물 안전관리 전수검사}

\section{1 제조소의 설치현황}

소방청 통계에 따르면 2020년 12월 31일 기준 전국 제조소 설치현황은 Table 5 와 같다. 전국에 총 2,375개소의 제조소가 설치되어 운영 중이며 지정수량의 10 배 미만의 위험물은 780 개소로 약 $32.8 \%$ 정도의 비율을 차지하는 것으로 나타났 다. 제조소가 가장 많이 설치된 지역은 경기도 580 개소로 약 $24.4 \%$ 의 비율을 차지하고 있었다.

통계에서 보는 바와 같이 소규모 제조소의 비율이 지정수 량의 배수를 구분한 범위에서 가장 많은 것에 비하여 여러 가지 완화규정을 적용하여 화재등의 재난에 대한 대응력이 약해질 수 있으므로 불필요한 완화규정을 삭제하여야 할 것으로 판단된다.

\section{2 소규모 제조소 전수검사}

소방청은 2021년 3월 18일 (주타코마테크놀러지 폭발사고 를 계기로 2021년 5월부터 6월까지 2개월간 소규모 제조소 780 개소에 대하여 전수검사를 실시하여 216개소에서 588건 의 위반사항에 대하여 적발 및 의법조치를 실시하였다. 검사 대비 적발비율은 약 $27.7 \%$ 로 소규모 제조소의 안전관리상태 가 취약한 상태임을 나타내고 있다.

주요 적발내용은 무허가 변경 18 건, 무허가 저장 17 건, 허가량 초과 10 건, 위험물취급자격자 미참여상태에서 취급 6건 등 총 66건에 대하여 입건, 품명 - 배수 변경신고 위반 8건, 저장 - 취급 세부기준 위반 2건, 안전관리자, 지위승계, 용도폐지 신고 위반 각 1 건 등 총 17 건에 대하여 과태료 처분, 보유공지 미확보, 급기구 인화방지망 불량, 피난 유도 등 점등불량, 방화문 불량, 집유설비 불량 등 보수명령 및 무허가 설비 철거명령 등 총 462건에 대하여 행정명령, 보유 공지 적치물 제거, 소화기 교체, 게시판 오기 수정 등 11 건에 대하여 현지시정한 것으로 나타났다(Nation Fire Agency 
Table 5. Factory Installation Status

\begin{tabular}{|c|c|c|c|c|c|c|c|c|c|c|c|}
\hline & \multirow[b]{2}{*}{ Total } & \multicolumn{10}{|c|}{ Multiple of the designated quantity (X) } \\
\hline & & $X<10$ & $\begin{array}{c}10 \\
\leq \mathrm{X}< \\
30\end{array}$ & $\begin{array}{c}30 \\
\leq \mathrm{X}< \\
100\end{array}$ & $\begin{array}{c}100 \\
\leq \mathrm{X}< \\
1,000\end{array}$ & $\begin{array}{c}1,000 \\
\leq \mathrm{X}< \\
3,000\end{array}$ & $\begin{array}{c}3,000 \\
\leq X< \\
20,000\end{array}$ & $\begin{array}{l}20,000 \\
\leq \mathrm{X}< \\
120,000\end{array}$ & $\begin{array}{l}120,000 \\
\leq X< \\
240,000\end{array}$ & $\begin{array}{l}240,000 \\
\leq X< \\
480,000\end{array}$ & $\begin{array}{c}480,000 \\
\leq X\end{array}$ \\
\hline Sum & 2,375 & 780 & 334 & 525 & 430 & 102 & 115 & 74 & 9 & 6 & - \\
\hline Seoul & - & - & - & - & - & - & - & - & - & - & - \\
\hline Busan & 52 & 25 & 8 & 13 & 6 & - & - & - & - & - & - \\
\hline Daegu & 17 & 6 & 3 & 6 & 2 & - & - & - & - & - & - \\
\hline Incheon & 40 & 21 & 4 & 9 & 1 & - & - & 4 & 1 & - & - \\
\hline Gwangju & 4 & 2 & 1 & - & 1 & - & - & - & - & - & - \\
\hline Daejeon & 21 & 6 & 4 & 10 & 1 & - & - & - & - & - & - \\
\hline Ulsan & 346 & 42 & 25 & 50 & 103 & 34 & 53 & 31 & 4 & 4 & - \\
\hline Sejong & 30 & 12 & 5 & 8 & 5 & - & - & - & - & - & - \\
\hline Gyeonggi & 580 & 279 & 114 & 129 & 57 & 1 & - & - & - & - & - \\
\hline Gangwon & 13 & 7 & - & 3 & 1 & 2 & - & - & - & - & - \\
\hline Chung-buk & 245 & 111 & 46 & 59 & 27 & 2 & - & - & - & - & - \\
\hline Chung-nam & 285 & 56 & 43 & 74 & 58 & 13 & 20 & 18 & 2 & 1 & - \\
\hline Jeon-buk & 159 & 28 & 16 & 54 & 54 & 7 & - & - & - & - & - \\
\hline Jeon-nam & 233 & 16 & 14 & 26 & 73 & 40 & 40 & 21 & 2 & 1 & - \\
\hline Gyeong-buk & 145 & 46 & 26 & 40 & 28 & 3 & 2 & - & - & - & - \\
\hline Gyeong-nam & 193 & 115 & 25 & 42 & 11 & - & - & - & - & - & - \\
\hline Changwon & 10 & 6 & - & 2 & 2 & - & - & - & - & - & - \\
\hline Jeju & 2 & 2 & - & - & - & - & - & - & - & - & - \\
\hline
\end{tabular}

119, 2021).

상기 적발내용에 따르면 평상시 제조소의 운영에 관련된 ‘위험물취급자격자 미참여상태에서 취급' 건을 제외한 나머 지 사항에 대하여는 정기점검을 통하여 사전에 예방할 수 있는 내용임을 알 수 있다. 다만, 앞서 언급한 바와 같이 정기점검이 안전관리자에 의해 수행되므로 위반사항을 숨 기고 점검항목에 기재하지 않는 경우에는 정기점검 실시 후 시·도지사를 통하여 제출된 정기점검표만으로 위반여 부를 확인할 수 없을 뿐만 아니라 정기점검제도를 시행하는 의미가 없어질 수 있으므로 외부 기관에 의한 점검이 이루어 질 수 있도록 관련법령을 개정하여야 할 것이다.

\section{5. 결 론}

위험물 소규모제조소의 화재사례 및 관련법령 등을 검토 한 결과 위험물 소규모 제조소의 안전한 관리를 위하여 다음과 같은 결론을 얻었다.

첫째, 근무형태에 따라 위험물안전관리자 또는 대리자가 위험물 취급하는 작업을 하는 동안 실질적인 관리가 될 수 있도록 상주하도록 하여야 하며, 대리자로 지정된 자도 선임신고를 의무화 하고 정기적으로 실무교육을 이수할
수 있도록 관련법령을 개정하여야 한다. 작업자는 공정 투입 전 위험물 안전관리자로부터 취급하는 위험물에 대한 안전 교육을 받아야 한다.

둘째, 소규모제조소라는 용어를 사용하고자 하는 경우 지 정수량의 10 배 미만으로 통일하고, 지정수량의 배수에 따른 보유공지의 폭도 세분화하여야 한다. 안전거리도 NFPA400 기준과 같이 지정수량의 배수 등에 따라 차등하여 적용할 수 있도록 관련법령을 개정할 필요가 있다.

셋째, 예방규정 및 정기점검의 대상을 모든 대상으로 확대 하고 정기점검의 경우 위험물 안전관리대행기관 등으로 외부기관에 의해 점검을 실시하도록 하고 시설 및 장비를 갖춘 법인은 제한 없이 안전관리대행기관으로 등록할 수 있도록 관련법령을 개정하여야 한다.

넷째, 강습교육 및 소방공무원 근무경력을 위험물안전관 리자의 자격으로 인정하지 않고 위험물안전관리자 시험응시 를 위한 응시자격으로 하는 객관적인 평가를 통해 위험물안 전관리자 자격을 취득하도록 관련법령을 개정하여야 한다.

본 연구를 통하여 위험물 소규모 제조소에서 위험물을 안전하게 취급하여 화재 및 폭발, 누출 등의 사고가 감소될 수 있기를 기대한다. 


\section{References}

GOODMORNINGCC. (2014). Daejeon industrial complex explosion fire, 1 killed, 7 injured. Retrieved November 22, 2014, from http://www.goodmorningcc.com/new s/articleView.html?idxno=22041

HANKOOKILBO. (2018). Goyang oil tank fire, damage increa sed due to fire extinguisher failure. Retrieved October 8, 2018, from https://www.hankookilbo.com/News/R ead/201810081604071102

Hyun, S.H., Song, Y.S., and Jung, D.K. (2007). A study on improvement of hazardous material safety supervisor lecturing education. Journal of Korean Institute of Fire Sci. \& Eng, Vol. 21, No. 1, pp. 29-36.

Lee, I.S. (2021). A study on the improvement of the safety management agency system for hazardous materials. The Graduate School Korea University of Technology Education, p. 49.

Nation Fire Agency 119. (2021). Strengthen safety management of small-scale hazardous substance factories. Retrieved July 29, 2021, from www.nfa.go.kr/nfa/news/pressrel ease/press/
Nation Fire Data System (NFDS). (2021). Nonsan fire station, fire site investigation report. Retrieved May 24, 2021, from https://nfds.go.kr

National Fire Protection Association. (2019). Hozardous materials code. Retrieved July 17, 2019, from https://nfpa.org NEWS1. (2016). 49 people involved in 'Tianjin Port Explosion' in China suspended the death penalty, severe sentences including weapons. Retrieved November 10, 2016, from https://www.news1.kr/articles/?2827460

NEWS1. (2021). Nonsan LCD manufacturing plant explosion fire, 1 killed, 9 seriously injured. Retrieved May 18, 2021, from https://www.news1.kr/articles/?4245376

Park, K.J., Shin, S.K., Lee, B.W. (2020). A study on revise the rule of safety controllers of hazardous substances. Journal of the Korean Society of Industry Convergence, Vol. 23, No. 3, pp. 473-480.

\begin{tabular}{l|l} 
Received & October 7, 2021 \\
Revised & October 14, 2021 \\
Accepted & November 12, 2021
\end{tabular}


